\title{
Torsional Oscillations Mitigation via Interval Type-2 Fuzzy Logic Brake Control
}

\author{
Mohamed Fayez Ahmed $^{1 *}$, Fahmy Bendary ${ }^{2}$, Mohamed El-Hadidy ${ }^{3}$ and Mohamed Adel Mandor ${ }^{2}$ \\ ${ }^{1}$ Faculty Cairo Electricity Production Company, Cairo, Egypt. \\ ${ }^{2}$ Faculty of Engineering, The University of Benha, Cairo, Egypt. \\ ${ }^{3}$ Egyptian Electricity Holding Company, Cairo, Egypt. \\ *Corresponding author: eng_mf69@yahoo.com, Tel: +20 01063221535
}

\begin{abstract}
Turbine-generator shaft torsional oscillations is an interdisciplinary power system dynamic problem because it encompasses mechanical and electrical sectors of power grids. They give rise to a premature expenditure of fatigue life of the turbine-generator shaft metal which could lead to shaft cracks. This paper introduces an interval type-2 fuzzy logic controller to regularize the dynamic braking interventions of a novel braking resistor model for mitigation of torsional oscillations resulting from unsuccessful autoreclosure procedures near generation stations. The effectiveness of proposed scheme is elucidated by considering the unsuccessful autoreclosure of three-phase-to-ground fault in a single machine infinite bus power system via MATLAB/Simulink-based modeling and simulation environment with the help of interval type-2 fuzzy logic controller toolbox. The comparative simulation results with and without the suggested mitigation regime show that the proposed scheme is effective in the mitigation of torsional torque oscillations.
\end{abstract}

Keywords: Dynamic brake resistance, Interval type-2 fuzzy logic, MATLAB/Simulink, Torsional oscillations.

Article History: received 24 June 2020; accepted 13 August 2020; published 29 August 2020.

\section{INTRODUCTION}

The rotating shaft of large utility-scale steam turbinegenerator is a heavily complicated mechanical structure [1]. Its complexity comes from the numerous components composing the mechanical structure of the shaft [1]. It composes of massive rotor elements, each one has considerable inertia and relatively large diameter, rigidly coupled in tandem at the thinner shaft extensions [1]. Other crucial components are also involved in the shaft composition such as, among others, turbine blades (buckets), mechanical bearing oil pump, hydrogen blowers, retaining rings, and excitation system components [1]. The shaft system is coupled with the electrical grid via electromagnetic torque in the generator air gap [2]. Turbine-generator shaft torsional oscillations is an interdisciplinary power system dynamic problem because it encompasses mechanical and electrical sectors of power grids [2]. The problem of torsional oscillations is a widely recognized power system operational problem from the viewpoint of the electric power utilities and a major design problem with great concern from the viewpoint of the machine manufacturers [2].

Abrupt changes in the electromagnetic torque cause the shaft system to experience multi-modal torsional oscillations [2]. These abrupt changes happen due to the network disturbances such as transmission line switching, generator malsynchronization, faults, fault clearings, and automatic reclosure [2]. The turbine-generator rotor shaft is modeled as a spring-mass model for elucidating the torsional oscillation at the shaft sections [3].
The automatic reclosure, autoreclosure for short, is an absolutely necessary protection and control scheme for extra-high voltage (EHV) overhead transmission lines carrying bulk power transactions in particular [3]. Autoreclosure was primarily engineered for improving the power system stability and boosting the system security since fault statistics manifest that over $80 \%$ of aerial transmission lines faults are transitory in nature [3]. Thus, several autoreclosure schemes have been indispensably employed all over the world for decades [3]. Intuitively, the reclosure will be unsuccessful in the case of permanent faults. The timing of fault clearing and circuit breaker autoreclosure determine whether the shaft torsional oscillations arising due to the fault and the consequent clearing process are attenuated (pleasant timing sequence) or exacerbated (unpleasant timing sequence) [3]. The exacerbation of shaft torsional oscillations, especially for unsuccessful reclosure, jeopardizes mechanical integrity of the turbine-generator by rapidly consuming the strategic fatigue life of the shaft material leading to shaft cracks or even complete shaft fracture [3]. Premature fatigue life expenditure of the turbine-generator shaft due to the unsuccessful reclosure is totally unacceptable by the machine manufactures [3]. Major turbine-generator manufacturers have made recommendations that the autoreclosure should be curtailed near generating stations despite its considerable merits [3]. The overwhelming advantages of autoreclosure, especially for transmission lines emanating from generating stations, have made it so significant to compromise between the necessity of 
employing it and the manufactures concerns [3, 4]. The torsional oscillations are inherently poor damped which makes the unsuccessful reclosure events to imposes devastating torsional torque oscillations characterized by very slow decaying rates in the nearby turbine-generators [4].

To compromise between the utilization of automatic reclosure near generating stations and the concerns of turbine-generator manufactures, torsional oscillations should be mitigated. The dynamic braking resistor is a cost-effective mitigation candidate for the shaft torsional oscillations [5]. Dynamic braking resistor was first engineered for improving the transient stability of the power system [5]. The resistor brake functions as a synthetic electric load which will be energized to dissipate the excess electric energy developed due to severe and deenergized elsewhere [5]. The dissipation of excess energy restrains the overspeed conditions of the nearby generators and thereby, improving the transient stability of the system [5]. Bonneville Power Administration (BPA) have utilized one of the largest ever-existing dynamic braking installations in the world with power dissipation capacity of $1400 \mathrm{MW}$ [5].

Multiple works of literature have addressed the employment of dynamic braking resistor linked to the network through a three-phase $\mathrm{AC}$ voltage controller, i.e. thyristor controlled braking resistor (TCBR), for tempering shaft torsional oscillations [6-11]. The perphase model of TCBR is constructed as two anti-parallelconnected power thyristors with the single resistor unit in series which means that three resistor units are employed for mitigation of torsional oscillations [6-11]. Recently, a novel braking resistor model, namely Chopper Rectifier Controlled Braking Resistor (CRCBR) model, is proposed as an alternate technique for the employment of dynamic braking interventions in power systems for enhancing the transient stability $[12,13]$. In $[12,13]$, the authenticity of utilizing CRCBR for transient stability enhancement in single machine infinite bus (SMIB) system and the Western System Coordinated Council (WSCC), 3machine 9-bus system have been explored. CRCBR controlled via an interval type-2 fuzzy logic controller (FLC) is proposed in this work for mitigation torsional oscillations arising from unsuccessful autoreclosure. CRCBR is fundamentally a single braking resistor bank connected to the three-phase terminals of the synchronous generator via a three-phase full-wave uncontrolled rectifier diode bridge and chopper switch (CS) [12, 13]. No similar work could be found in the literature, to date, regarding the utilization of CRCBR for mitigation of multimodal shaft torsional oscillations resulting from unsuccessful reclosure. The CRCBR is either is either energized or deenergized based on the control signal generated by the interval type- 2 FLC. The generator mass speed deviation in p.u. is implemented in this work as a local control input signal to the Interval Type-2 FLC for strategizing the CRCBR dynamic braking interventions. The impact of the proposed scheme in tempering torsional oscillations is demonstrated in using the SMIB power system via MATLAB/Simulink-based modeling and simulation platform with the help of the Interval Type-2 FLC toolbox.
Comparative simulation study of the test system with and without the proposed mitigation regime should demonstrate its effectuality for mitigation of shaft torsional torque oscillations.

The rest of this article is arranged as follows. In section 2 , the well-known test system is briefly described. In section 3 the concept of utilizing the Interval Type-2 FLC to orchestrate the switching strategy of the CRCBR is introduced. In section 4, MATLAB/Simulink time domain simulation results are delineated with a discussion. In section 5, the key conclusions of this work are drawn. Then, the references used in this work are listed. Finally, the parameters of the of the system under study are tabulated in the Appendix Section.

\section{TEST SYSTEM DESCRIPTION}

To scrutinize the effectiveness of the proposed mitigation regime in this paper, the SMIB model is utilized. Figure 1 presents the single line diagram of the system under study together with CRCBR and the steam turbine-generator shaft detail $[12,14]$. The model is basically a single synchronous generator (rated as $892.4 \mathrm{MVA} / 20 \mathrm{kV} / 60$ $\mathrm{Hz} / 3600 \mathrm{rpm}$ ) connected to an infinite bus through generator step-up transformer (rated as 900 $\mathrm{MVA} / 20 \mathrm{kV} / 500 \mathrm{kV}$ ) and two $200 \mathrm{~km}$ EHV transmission lines $[14,15]$. The generator (Gen.) is driven by one singleflow high-pressure (HP) steam turbine, one single-flow intermediate-pressure (IP) steam turbine and two doubleflow low-pressure (LP) steam turbines connected in tandem [14, 15]. The parameters of the synchronous generators and its corresponding turbine-generator shaft data are taken from the well-known IEEE first benchmark model originally implemented for subsynchronous resonance (SSR) studies [15], and are tabulated in the Appendix Section. The model of CRCBR composed of one braking resistor bank linked to the generator terminals through six-pulse full wave uncontrolled Rectifier Bridge and a chopper switch as shown in Figure 1 [12, 14]. Insulated Gate Bipolar Transistor (IGBT) is employed in this work as a chopper switch. The CRCBR is assumed to be capable of dissipating $200 \mathrm{MW}$.

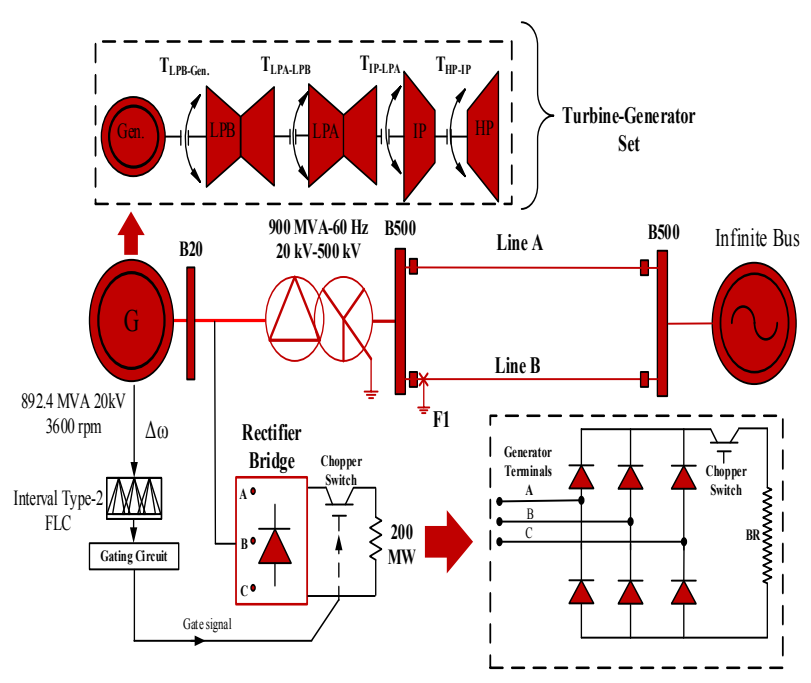

Figure 1. SMIB model with shaft multi-mass model incorporating CRCBR device [12, 14] 
The CRCBR is energized or de-energized by the IGBT switch to dissipate the acceleration excess energy and thereby tempering the shaft torsional oscillations. The generator mass speed deviation is utilized as a local control signal to help the interval type-2 FLC determine whether the CRCBR should be energized or de-energized. The system is completely modeled in MATLAB/Simulink environment. Static excitation system of IEEE ST1A type is used in the simulation study and it is implemented by Simulink ST1A excitation system block with parameters obtained from [14]. The configuration of the considered steam turbine in this study is appropriately illustrated in [15]. The turbine contributing torque fractions for the turbine sections HP, IP, LPA, and LPB are $30 \%, 26 \%$, $22 \%$, and $22 \%$, respectively [15]. The parameters of the transmission lines are obtained from [14] and are listed in the Appendix Section.

\section{FUZZY LOGIC CONTROLLER}

All the controllers based on fuzzy logic often give improved results in comparison with the other conventional controllers [16]. FLCs have been recommended for the control problems characterized by their sophisticated nature and the ambiguity of their control variables [16]. FLCs provide a superior control level by incorporating the expert knowledge concept in solving multidisciplinary control problems [16]. FLCs are comprehensively employed for fixing the vast majority of power system problems such as, among others, damping of the power system oscillatory behavior, load forecasting, fault diagnosis, power system stability enhancement, scheduling of generator maintenance, economic load dispatch, and unit commitment [17].

The aforementioned applications are commonly accomplished via exploiting the classic type-1 FLCs [15]. A modern class of FLCs has emerged to the ArtificialIntelligence based control applications, namely, Interval Type-2 FLCs [17]. Interval Type-2 FLCs have been recently implemented for solving many power system dynamic problems as a more superior alternate for type-1 FLCs [17-23]. Interval Type-2 FLCs are based on the concept of Interval Type-2 Fuzzy Set (IT2 FS) which was first introduced to the academic community by Lotfi Zadeh in 1975 as a sequel to his traditional Type-1 fuzzy set (T1 FS) concept [24-26]. The membership degree of an IT2 FS is an interval-valued fuzzy set, unlike a classical T1 FS in which the membership degree is a definite crisp value between zero and one [24-26]. IT2 FS is very useful in control problems characterized by the awkwardness of deciding the proper membership function for a fuzzy set [24-26]. The block diagram of a general type-2 FLC is depicted in Figure 2 [24-26].

Takagi-Sugeno-Kang (TSK) inference engine is selected in this article and the rule consequent is constant (i.e. zero-order type-2 Sugeno model). In TSK inference engine the necessity for type reduction and defuzzification is diminished and thereby the computational burden is minified in a relative manner [24-26]. The proposed Interval Type-2 FLC is designed with the help of the Interval Type-2 FLC toolbox presented in [27].

The generator mass speed deviation is selected as the input signal to the Interval Type-2 FLC since it achieves better damping levels than the damping acquired from selecting other speed deviation signals such as HP, and/or LP speed signals [14]. Generalized bell membership functions of type-2 are selected to represent the fuzzy sets employed in this work and are shown in Figure 3. Three linguistic variables, namely, NB (Negative Big), Z (Zero), and $\mathrm{PB}$ (Positive Big) are defining the type-2 fuzziness of the controller's input. The parameters of the membership functions are determined by trial and error according to the generator mass speed deviation swing range based on an extensive simulation study.

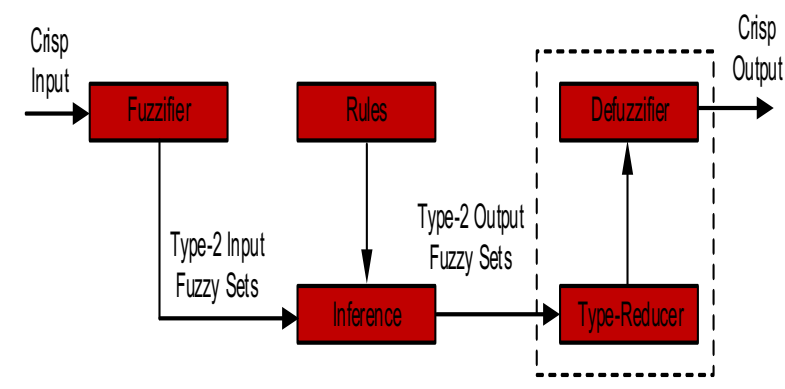

Figure 2. A general structure of Type-2 FLC [25]

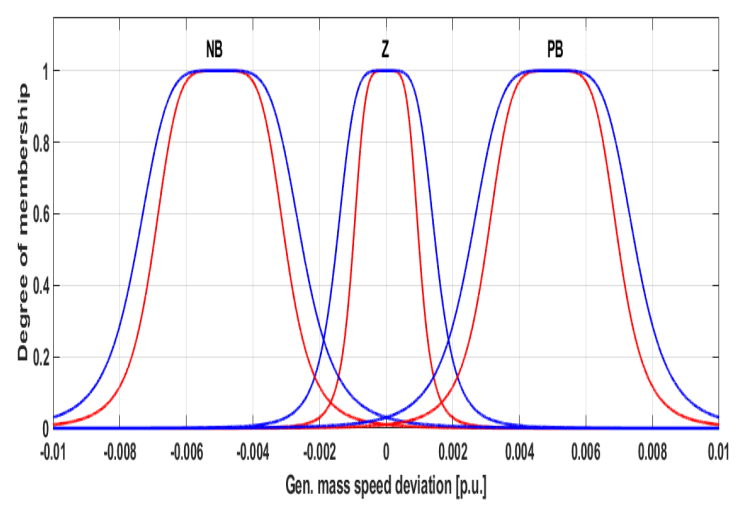

Figure 3. Interval type-2 fuzzy logic controller input membership functions in p.u.

Like the rules structure in Type-1 FLC, the rules in Interval Type-2 FLC take the form "IF Rule AntecedentTHEN Rule Consequent" statements [24]. In Interval Type-2 FLC, the antecedent and/or the consequent of the rule are of IT2 FS. A group of fuzzy rules, each fuzzy rule uses IT2 FS would point out the control decisionmaking mechanism for deciding the convenient decision output for the different system stimuli. Despite the relative complexity of the IT2 FLC, the proposed brake control scheme is very simple since there are only three fuzzy control rules. Intuitively, the CRCBR should be put into service if the generator mass speed surpasses a dead-band value (i.e. the acceleration state) and remove from service elsewhere (i.e. the steady state and deceleration state). Thus. the IT2 fuzzy rules are as follows, IF $\Delta \omega$ is NB THEN output is 0 , IF $\Delta \omega$ is Z THEN output is 0 , and IF $\Delta \omega$ is PB then the output is 1 . Where 0 indicates that the CRCBR should be OFF and 1 indicates that theCRCBR should be ON.

\section{SIMULATION RESULTS}


For the intent of assessing the effectiveness of the proposed scheme in mitigating the shaft torsional oscillations arising from unsuccessful autoreclosure, time domain simulation study via Simulink model and IT2 FLC toolbox is conducted taking into consideration the worstcase scenario. Three-phase to ground fault (3LG) is applied at line B, very close to generator high voltage bus at fault point F1, as shown in Figure 1. The fault is applied at 0.25 second from the simulation time of 5 seconds. The timings of the circuit breakers are assumed to be 3 cycles ( 0.05 second $)$ for fault clearing, 30 cycles $(0.5$ second $)$ for autoreclosure and 3 cycles $(0.05$ second $)$ for fault reclearing. The chosen timing sequences cause the torsional torque responses to be exaggerated for imposing extreme torsional stress on the shaft system. The system torsional torque profiles in p.u. with and without the IT2 FLC controlled CRCBR are delineated in Figure 4. Correspondingly, the speed deviation responses of different masses of the shaft system with and without the IT2 FLC controlled CRCBR are listed as a family of curves shown in Figure 5.

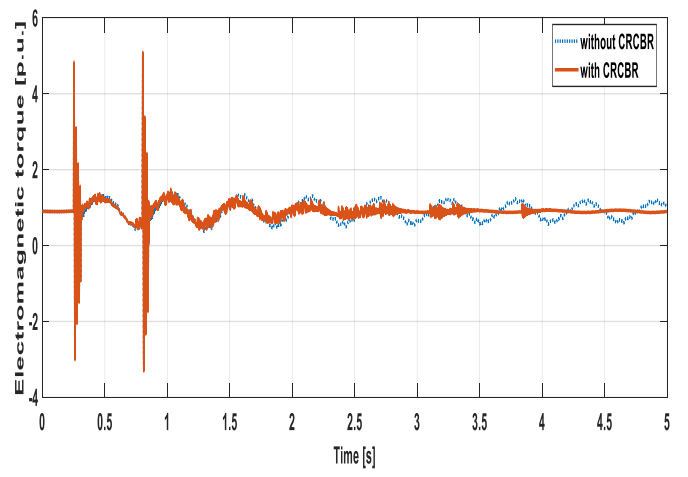

(a) Electromagnetic torque

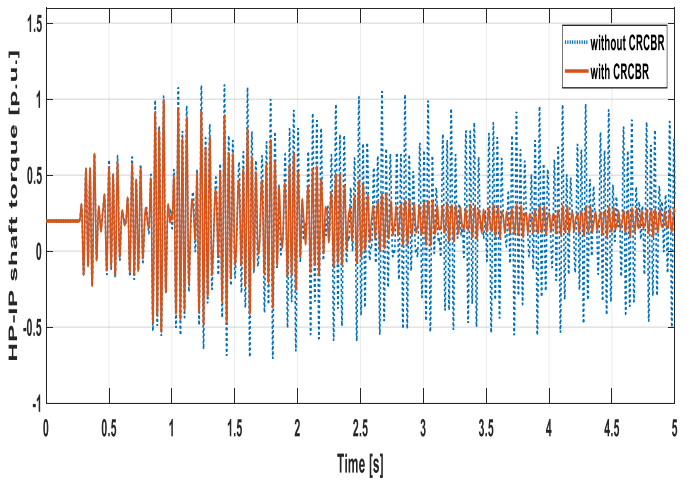

(b) HP-IP shaft torque

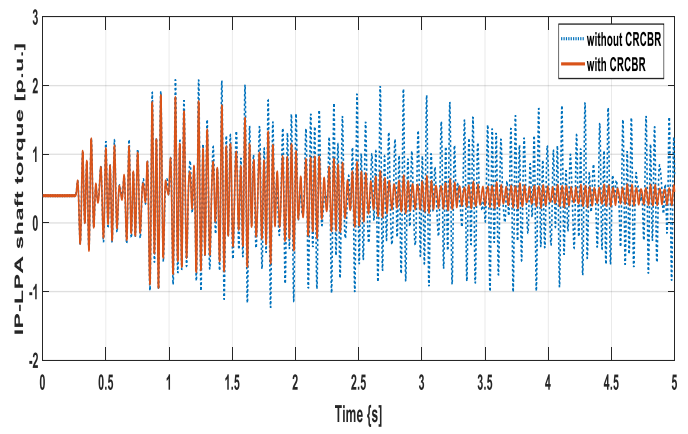

(c) IP-LPA shaft torque

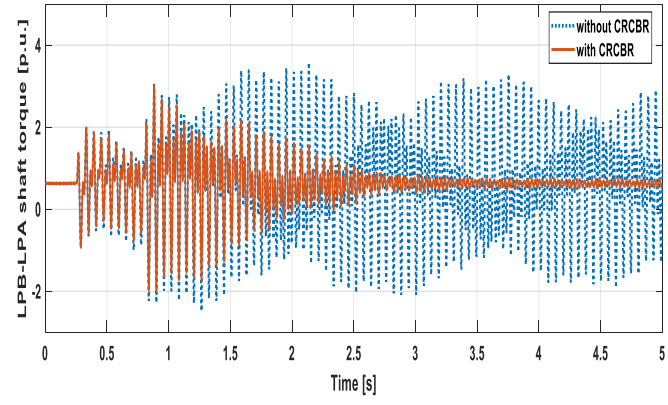

(d) LPA-LPB shaft torque

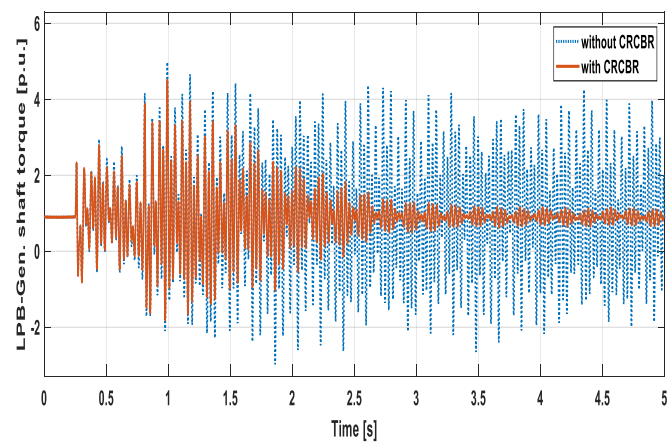

(e) LPB-Gen. shaft torque

Figure 4. Torque responses with and without IT2 FLC controlled CRCBR for unsuccessful reclosure of $3 \mathrm{LG}$ fault

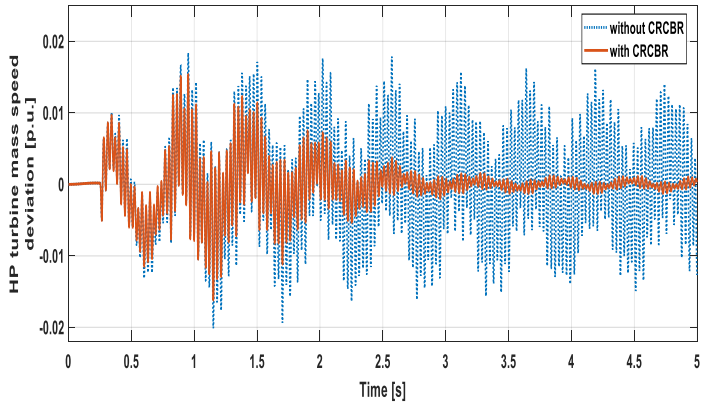

(a) HP turbine mass speed deviation

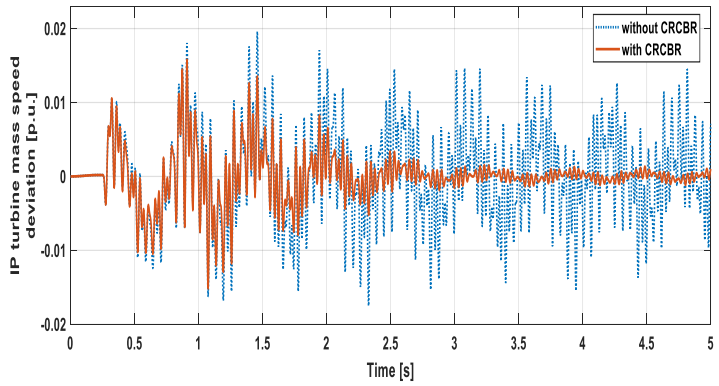

(b) IP turbine mass speed deviation 


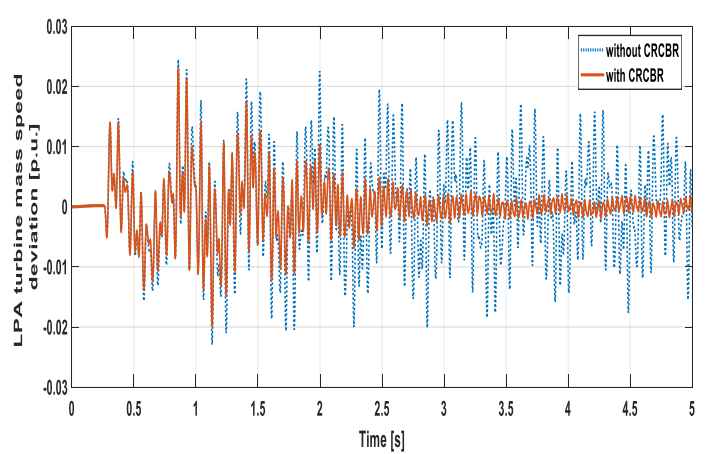

(c) LPA turbine mass speed deviation

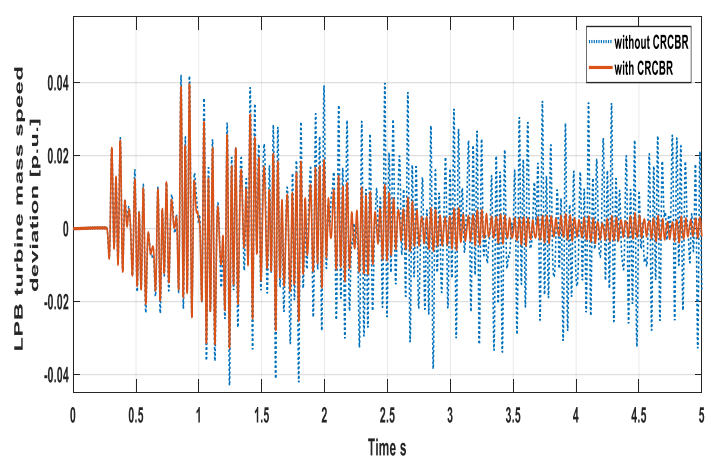

(d) LPB turbine mass speed deviation

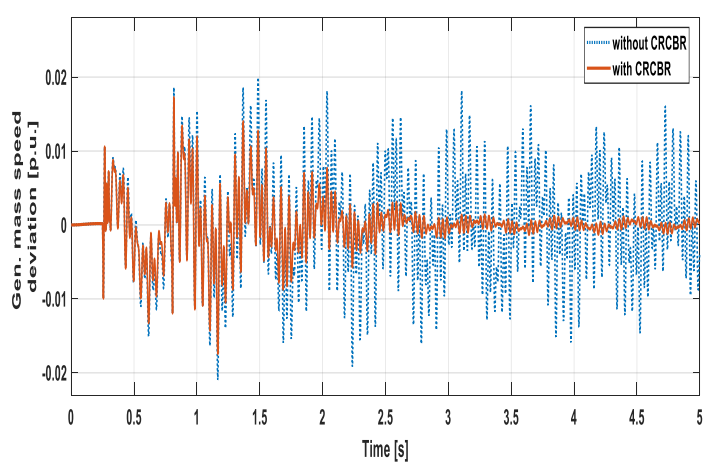

(e) Generator mass speed deviation

Figure 5. Speed responses with and without IT2 FLC controlled CRCBR for unsuccessful reclosure of $3 \mathrm{LG}$ fault

From the simulation results delineated in Figures 4 and 5, in the base case results without the supplemental damping scheme, it is obviously noticed that, the torsional torque profiles have encountered severe oscillations with devastating magnitudes which seem to be sustained in the time frame of the simulation due to the inherent weak damping associated with the torsional oscillatory behavior. These torque oscillations cause the turbine-generator units to be more vulnerable to the commencement and propagation of fatigue cracks with the consequent probable shaft fracture. Also, the oscillatory behavior of the relative speed responses of the different masses is clearly observed.

Due to applying the CRCBR, it is clearly shown that both of torsional torque and the relative speed responses of the shaft system have experienced outstanding supplemental damping. The mitigation of the shaft torsional oscillations permits the utilization of automatic reclosure safely and soundly near the generating stations without jeopardizing the mechanical integrity of the turbine-generators.

\section{CONCLUSIONS}

CRCBR is an effective method for mitigation of torsional oscillations. This paper authenticates the effectiveness of CRCBR controlled through IT2 FLC for mitigation of shaft torsional oscillations arising from the unsuccessful autoreclosure in SMIB power system. From the obtained simulation results, the torsional torque profiles of the turbine-generator shaft system manifest a significantly good supplemental damping which permits the shaft torsional oscillations to virtually die out speedily. CRCBR is believed to be a viable technique for tempering shaft torsional torque oscillations and thereby boosting the operational security of the turbine-generator by extending its fatigue life to the maximum span potential.

\section{REFERENCES}

[1] P. Kundur, Power System Stability and Control, New York: Tata McGraw-Hill, Inc., 1994.

[2] D. N. Walker, Torsional Vibration of Turbomachinery, New York: McGraw-Hill, 2003.

[3] P. M. Anderson, Power System Protection, New Jersey: John Wiley \& Sons, 1999.

[4] G. Klempner, and I. Kerszenbaum, Handbook of large Turbo-Generator Operation and Maintenance, New Jersey: John Wiley \& Sons, 2008.

[5] M. F. Ahmed, M. A. Ebrahim, M. A. El-Hadidy, and W. M. Mansour, "Torsional oscillations mitigation for interconnected power system via novel fuzzy control based braking resistor model," Presented at conseil international des grands réseaux électriques (CIGRÉ), Paris, France, pp. $1-9$, August 26-31, 2018.

[6] O. Wasynczuk, "Damping Shaft Torsional Oscillations Using A Dynamically Controlled Resistor Bank," IEEE Trans. Power Apparat. Syst., vol. 100, pp. 3340 - 3349, July 1981.

[7] R. M. johnson, Dynamic Brake Control to Reduce Turbine Shaft Transient Torque. Electric Power Research Institute (EPRI), Report number: 103902, 1994.

[8] M. H. Ali, M. Park, and In-Keun Yu, "Minimization of Shaft Torsional Oscillations by Fuzzy Controlled Braking Resistor Considering Communication Delay,"WSEAS Trans. Power Syst., vol. 3, pp. 174 - 179, March 2008.

[9] M. H. Ali, M. Park, In-Keun Yu, T. Murata, and J. Tamura, "Coordination of Fuzzy Controlled Braking Resistor and Optimal Reclosing for Damping Shaft-Torsional Oscillations of Synchronous Generator," International Conference on Electrical Machines and Systems (ICEMS), Korea, 2007, pp. 1259 - 1264.

[10] M. H. Ali, T. Mikami, T. Murata, and J. Tamura, "A Fuzzy Logic Controlled Braking Resistor Scheme for Damping Shaft Torsional Oscillations," IEEJ Trans. on P. E., vol. 124, pp. $207-214,2004$.

[11] M. H. Ali, T. Murata, and J. Tamura, "Effect of Fuzzy Controlled Braking Resistor on Damping Turbine Generator Shaft Torsional Oscillations During Unsuccessful Reclosing," International Review of Electrical Engineering (IREE), vol. 1, pp. 711-718, 2006.

[12] R. Saluja, and M. H. Ali, "Novel Braking Resistor Models for Transient Stability Enhancement in Power Grid System," IEEE PES Innovative Smart Grid Technologies (ISGT) Conference, Washington DC, USA, 2013, pp. $1-6$. 
[13] R. Saluja, S. Ghosh, and M. H. Ali, "Transient Stability Enhancement of Multi-Machine Power System by Novel Braking Resistor Models," IEEE Southeast Conference, Florida, USA, 2013, pp. $1-6$.

[14] M. Fayez Ahmed, M. A. Ebrahim, M. A. El-Hadidy, and W. M. Mansour "Torsional Oscillations Mitigation via Novel Fuzzy Control Based Braking Resistor Model," International Electrical Engineering Journal (IEEJ), vol. 7, pp. $2173-2181,2016$.

[15] IEEE Subsynchronous Resonance Task Force of the Dynamic System Performance Working Group Power System Engineering Committee, "First Benchmark Model for Computer Simulation of Subsynchronous Resonance," IEEE Trans. on Power Apparat. Sys., vol. 96, pp. 1565 1572, October 1977.

[16] I. H. Altaş, Fuzzy Logic Control in Energy Systems with Design Applications, Stevenage, United Kingdom: Institution of Engineering \& Technology (IET), 2017.

[17] M. K. Panda, G. N. Pillai, V. Kumar, "Power system stabilizer design: interval type-2 fuzzy logic controller approach," Proceedings of the international conference on power control and embedded systems, Allahabad, India, pp. 1-10, December 17-19, 2012.

[18] A. Sharma, L. K. Nagar, N. P. Patidar, M. L. Kolhe, S. R. Nandanwar, V. N. Puranik, and V. K. Singh, "Minimizing uncertainties with improved power system stability using wide area fuzzy-2 logic-based damping controller," Proceedings of 3rd IEEE International Conference on "Computational Intelligence and Communication Technology" (IEEE-CICT), Ghaziabad, India, pp. 1-5, February 9-10, 2017.

[19] M. K. Sharma, A. Vijay, and G. N. Pillai, "Stable Type-2 Fuzzy Logic Control of TCSC to Improve Damping of Power Systems," International Conference on Computer, Communications and Electronics. Jaipur. 2017: pp. 388393.

[20] K. Saoudi, Z. Bouchama, M. Ayad, M. Benziane, and M. N. Harmas, "Design of a robust PSS using an indirect adaptive type-2 fuzzy sliding mode for a multi-machine power system," Proceedings of international conference on modelling, identification and control, Algiers, Algeria, pp. 713-718, November 15-17, 2016.

[21] M. Tripathy, and S. Mishra, "Interval Type-2-Based Thyristor-Controlled Series Capacitor to Improve Power System Stability," IET Gener. Transm. \& Distrib., vol. 5, pp. 209-222, 2011.

[22] S. Kamel, B. Ziyad, H. M. Naguib, A. Mouloud, and R. Mohamed, "An indirect adaptive type-2 fuzzy sliding mode PSS design to damp power system oscillations," Proceedings of International Conference on Modelling, Identification and Control (ICMIC), Sousse, Tunisia, pp. 16, December 18-20, 2015.

[23] S. K. Raju, and G. N. Pillai, "Design and Implementation of Type-2 Fuzzy Logic Controller for DFIG-Based Wind Energy Systems in Distribution Networks," IEEE Trans. Sustain. Energy, vol. 7, pp. 345-353, January 2016.

[24] O. Castillo, and P. Melin, Type-2 Fuzzy Logic: Theory and Applications. Berlin: Springer-Verlag Berlin and Heidelberg GmbH\& Co, 2008.
[25] R. Antão, Type-2 Fuzzy Logic Uncertain Systems' Modelling and Control. Singapore: Springer, 2017.

[26] O. Castillo, L. T. Aguilar, Type-2 Fuzzy Logic in Control of Nonsmooth Systems: Theoretical Concepts and Applications. Cham, Switzerland: Springer Nature Switzerland AG, 2018.

[27] A. Taskin, and T. Kumbasar, "An Open Source Matlab/Simulink Toolbox for Interval Type-2 Fuzzy Logic Systems," IEEE Symposium Series on Computational Intelligence, South Africa, 2015, pp. 1561-1568.

\section{APPENDIX:}

\section{- Turbogenerator Parameters}

The Steam Turbine and Governor MATLAB/Simulink block is utilized to implement a four-mass steam turbine. The turbinegenerator shaft detailed mechanical data are tabulated in Table 1 [15].

Table 1. Turbine-generator shaft detailed parameters

\begin{tabular}{|c|c|c|c|}
\hline Mass & Shaft & $\begin{array}{c}\text { Intertia H } \\
\text { (s) }\end{array}$ & $\begin{array}{l}\text { Spring constant } K \\
\text { p.u. torque/rad. }\end{array}$ \\
\hline HP & & 0.092897 & \\
\hline & HP-IP & & 19.303 \\
\hline IP & & 0.155589 & \\
\hline & IP-LPA & & 34.929 \\
\hline LPA & & 0.858670 & \\
\hline & LPA-LPB & & 52.038 \\
\hline LPB & & 0.884215 & \\
\hline Gen. & LPB-Gen. & 0.868495 & 70.858 \\
\hline
\end{tabular}

The synchronous generator MATLAB/Simulink block is utilized in our study to implement a synchronous generator in the simulations study and the electrical parameters are tabulated in Table 2 [13].

Table 2. Synchronous generator electrical parameters

\begin{tabular}{|c|c|c|c|c|}
\hline Gen. & \multicolumn{4}{|c|}{ 892.4 MVA, 2 pole, $60 \mathrm{~Hz}, 20 \mathrm{kV}$} \\
\hline$\overline{X_{d}}$ & 1.790 & p.u. $\quad \mathbf{X}_{q}$ & 0.20 & p.u. \\
\hline $\mathbf{X}_{\mathrm{d}}$ & 0.169 & p.u. $\quad \mathbf{T}_{\text {do }}$ & 4.30 & $\mathrm{~s}$ \\
\hline $\mathbf{X}_{\mathrm{d}}$ & 0.135 & p.u. $\quad \mathbf{T}_{\text {do }}$ & 0.03 & $\mathrm{~s}$ \\
\hline $\mathbf{X}_{1}$ & 0.130 & p.u. $\quad \mathbf{T}_{\text {qo }}$ & 0.85 & $\mathrm{~s}$ \\
\hline $\mathbf{X}_{\mathbf{q}}$ & 1.710 & p.u. $\quad \mathbf{T}_{\text {qo }}^{.90}$ & 0.05 & $\mathrm{~s}$ \\
\hline$X_{q}^{*}$ & 0.228 & p.u. $\quad \mathbf{R}$ & 0.00 & p.u. \\
\hline
\end{tabular}

\section{- Transmission System Parameters}

The $500-\mathrm{kV}$ transmission system is of the double circuit arrangement and is represented in the model using distributed line parameters MATLAB/Simulink block. The length for each line is $200 \mathrm{~km}$. The electrical parameters of each line are the resistance per unit length is $0.01165 \Omega / \mathrm{km}$, the inductance per unit length is $0.8679 \times 10^{-3} \mathrm{H} / \mathrm{km}$, and the capacitance per unit length is $13.41 \times 10^{-9} \mathrm{~F} / \mathrm{km}[14]$. 